$14.4 \%, \mathrm{p}<0.001)$ and further treatment for SIL $(7.5 \%$ vs $4.8 \%, \mathrm{p}<0.001)$ compared to negative margin.

Conclusions Most women (85\%) with positive margin went without residual/recurrent HSIL, of which the option of close surveillance with cytology is reasonable. Repeat excision may be considered in selected women with positive margin, endocervical glandular involvement and those who are older or unable to comply with follow-up.

\section{EPV235/\#261 OUTCOMES FOLLOWING REFERRAL TO COLPOSCOPY WITH A HIGH-GRADE SMEAR IN WOMEN AGED 50 YEARS AND ABOVE}

R Shah*, E Leung, D Mukhopadhyay. Queen's Hospital, Barking, Havering and Redbridge University NHS Trust, Gynaecologic Oncology, London, UK

\subsection{6/ijgc-2021-IGCS.306}

Objectives Interpretation of smears is a challenge in older women owing to atrophic changes. Colposcopy can be difficult and views are often unsatisfactory. Approximately $60 \%$ of cervical cancers occur in women aged 45 plus; evidence shows a second peak of high-risk HPV in postmenopausal women. This study aims to establish whether high-grade smear cytology correlates with colposcopic and histological findings in women aged 50 or above and review the employed subsequent management.

Methods A retrospective study was conducted of all women aged 50 years and above, referred to Queen's Hospital colposcopy unit due to high-grade smear between 2016-2019. An electronic data search was undertaken to establish colposcopy findings, histology of biopsy, LLETZ, or further surgical intervention plus results following tests of cure. Data was analysed using Microsoft Excel.

Results Smear cytology for the 99 women referred demonstrated 1 suspicious of glandular neoplasia, 50 of severe, and 48 of moderate dyskaryosis. 11 patients were excluded due to incomplete data. Colposcopic views were unclear for $27(31 \%)$ patients. 82(93\%) patients underwent LLETZ. 3 squamous cell carcinomas and 1 adenocarcinoma were detected. High-grade histology was seen in 54 samples (23\% CINII and $38 \%$ CINIII), low-grade histology in $11(13 \%$ CINI), $11 \%$ had no abnormality and $10 \%$ displayed other benign changes. 10 patients went on to have a total hysterectomy and bilateral salpingo-oophorectomy.

Conclusions A 5\% incidence of cancer and 61\% high-grade histology was found in this cohort, with 11\% undergoing radical surgical intervention. This demonstrates the need for robust cervical screening programmes, particularly in conflicting smear and colposcopy findings.

\section{EPV236/\#321 CAN MIDWIVES EFFICIENTLY PERFORM CERVICAL CANCER SCREENING?}

${ }^{1} \mathrm{~K}$ Ben Hamida*, 'M Ghalleb, 'A Triki, 'I Jebir, ${ }^{2} \mathrm{D}$ Halleb, ${ }^{1} \mathrm{R}$ Makhlouf, ${ }^{1} \mathrm{H}$ Touinsi. ${ }^{1}$ Mohamed Taher Al-Maamouri Hospital, General Surgery Department, Nabeul, Tunisia; ${ }^{2}$ Family Planning Center of Nabeul, Women and Children Health Department, Nabeul, Tunisia

10.1136/ijgc-2021-IGCS.307
Objectives In Tunisia, cervical cancer is the third cancer in women affecting 250 to 300 women/year. Unfortunately, patients are still diagnosed in an advanced stage. Midwives hold a capital role in cervical cancer screening since they are the first line of our national screening program. We aim through this work to prove their efficiency in reducing the incidence of invasive cervical cancer.

Methods Data were collected from registries of the Family Planning Center of Nabeul, Tunisia, from January 2015 to December 2019.

Results From January 2015 to December 2019, 3745 PAP smears were performed (the mean number was 740 PAP smears per year). For 2801 women $(73.6 \%)$, it was the first time they had a PAP smear, and for 944 women (26.4\%), it was the second time. Time to response was 5.5 weeks (range 3 to 8.6). Normal cytology represented 74.74\%. Inadequate PAP smear represented only $2.1 \%$. The inflammatory cytology was rated $20.5 \%$. Atypical squamous cells of undetermined significance (ASC-US) represented $0.55 \%$ of all specimens. Low-grade squamous intraepithelial lesions (LSIL) were $0.94 \%$. High-grade squamous intraepithelial lesions (HSIL) represented $0.90 \%$.

Conclusions These data showed that midwives could correctly perform PAP smear, thereby confirming their substantial role in cervical cancer screening.

\section{EPV237/\#541 TWO-YEAR EFFECTIVENESS OF TOPICAL IMIQUIMOD TREATMENT OF HIGH-GRADE CERVICAL INTRAEPITHELIAL NEOPLASIA (TOPIC-3)}

${ }^{1} \mathrm{~N}$ Hendriks*, ${ }^{2} \mathrm{M}$ Koeneman, ${ }^{1} \mathrm{~B}$ Slangen, ${ }^{3} \mathrm{~A}$-J Krüse. 'Maastricht University Medical Center, Gynaecology and Obstetrics, Maastricht, Netherlands; ${ }^{2}$ Rivierenland Ziekenhuis, Obstetrics and Gynaecology, Tiel, Netherlands; ${ }^{3}$ Isala Clinics, Obstetrics and Gynaecology, Zwolle, Netherlands

\subsection{6/ijgc-2021-IGCS.308}

Objectives Imiquimod could be offered as a non-surgical treatment alternative to LLETZ in treatment of high-grade CIN, for women who wish to avoid surgery. Short term effectiveness of imiquimod is $60-70 \%$. In the current study, we present the two-year follow-up results after successful initial imiquimod treatment, compared to LLETZ treatment.

Methods We performed a multi-center, non-randomized trial, in which women with a histological diagnosis of CIN 2/3 were treated with either imiquimod during 16 weeks or

Abstract EPV237/\#541 Table 1 Two-year treatment effectiveness

\begin{tabular}{|c|c|c|c|}
\hline & $\begin{array}{l}\text { Imiquimod } N=27 \\
N(\%)\end{array}$ & $\begin{array}{l}\text { LLETZ N=57 } \\
N(\%)\end{array}$ & $p$-value \\
\hline $\begin{array}{l}\text { Successful treatment } \\
\text { at two year follow-up }\end{array}$ & $25(93)$ & $56(98)$ & \multirow[t]{2}{*}{$P=0.26$} \\
\hline $\begin{array}{l}\text { LLETZ treatment } \\
\text { during two year } \\
\text { follow-up }\end{array}$ & $2(7)$ & $1(2)$ & \\
\hline $\begin{array}{c}\text { CIN diagnosis } \\
-\quad C I N 2 \\
-\quad C I N 3\end{array}$ & $\begin{array}{l}2(100) \\
0\end{array}$ & $\begin{array}{l}0 \\
1(100)\end{array}$ & $P=0.33$ \\
\hline $\begin{array}{l}\text { HPV positive at two } \\
\text { year follow-up }\end{array}$ & $6 / 19(32)$ & $13 / 41(32)$ & $\mathrm{P}=0.99$ \\
\hline
\end{tabular}

